\title{
How Does Algorithmic Trading Influence Investor Participation in Peer-to- Peer Online Lending Markets?
}

\author{
Hongchang Wang \\ University of Texas at Dallas \\ hongchang.wang@utdallas.edu
}

\author{
Eric Overby \\ Georgia Institute of Technology \\ eric.overby@scheller.gatech.edu
}

\begin{abstract}
Algorithmic trading has reshaped equity markets and had significant effects on market performance. We examine the effect of algorithmic trading in online peer-to-peer lending markets. These markets were originally designed to be accessible to individual investors, however, because algorithmic trading is typically used by institutional investors with substantial resources, algorithmic trading threatens to shut individual investors out of the market. Ironically, this could exacerbate inequalities in the financial system that peer-to-peer lending markets were designed to help eliminate. To study the effects of algorithmic trading, we examine an API upgrade on Prosper.com that facilitated algorithmic trading. Using a difference-in-differences strategy, we find that individual "manual" investors were crowded out of the most quickly-funded and typically best-performing loans after the API upgrade. However, the API upgrade may have increased the size of the market, thereby allowing individual investors to continue investing in the market, albeit for somewhat lower quality loans.
\end{abstract}

\section{Introduction}

Decisions that were previously made by humans are increasingly being made by information systems. One example is algorithmic trading, which we examine in this study. Algorithmic trading, which can be loosely defined as "the use of computer systems to execute trading strategies" [1], has reshaped equity markets and had significant implications for market performance [2]. Algorithmic trading also raises questions about fairness, given that some market participants do not have the expertise or sophistication to use the technology. This may create an uneven playing field in which sophisticated investors who engage in algorithmic trading crowd out unsophisticated investors who do not.
We investigate the implications of algorithmic trading in the context of peer-to-peer lending. In peerto-peer lending, borrowers seeking loans create listings on web sites such as Prosper.com and LendingClub. Investors choose which of these borrowers to fund based on these listings. If a borrower's listing attracts enough investors, then s/he can receive the loan. In this context, we use the term "algorithmic trading" to refer to the practices of automated and data-driven decision making enabled by API. Peer-to-peer lending is an interesting context for our analysis for two reasons. First, as reflected by the "peer-to-peer" label, online lending markets were originally designed to connect individual (and presumably non-sophisticated) investors with borrowers. The original model was that these individual investors would access the web site manually to review listings and identify which of their "peers" they wanted to lend to. This model is changing as institutional investors fund an increasing percentage of online loans, largely via algorithms that select the loans automatically (and very quickly). This threatens to upend the traditional model upon which online lending originally flourished. Second, this context allows us to extend prior research on the effects of algorithmic trading. In most contexts in which algorithmic trading has been studied (e.g., the stock market), the same assets (e.g., stocks) may be bought and sold multiple times. This means that there are always opportunities for non-sophisticated investors to purchase or sell assets. This is not true of online loans. Once these loans are funded by an investor(s), they are no longer available to other investors. Thus, it is possible that algorithmic trading could allow sophisticated investors to capture the entire online lending market. Further, the ultimate impact of algorithmic trading in these markets is unclear. "Manual" investors argue that they are crowded out of the market because they cannot match the speed advantage of the algorithmic investors. Algorithmic investors argue that the algorithms help satisfy borrowers' needs more quickly and efficiently, which leads to market growth and more opportunity for all investors, including manual investors. 
We use data from Prosper.com to study the effects of algorithmic trading. Because we cannot directly observe which investors use algorithmic trading technologies, we study the effect of a policy change that facilitated algorithmic trading. On March 11, 2013, Prosper.com released a major upgrade to its API (Application Programming Interface). The new API made it easier to algorithmically select loans to fund by providing more data fields and improving response time. If the API helped institutional investors "crowd out" manual investors via algorithmic trading strategies, then we should see the followings after the release of the new API: high-quality loans being funded very quickly (too quickly to be funded manually) and by a relatively small number of investors who loan large amounts. Using a differencein-differences strategy, we find precisely that. This suggests that manual investors are being "crowded" out of the market by algorithmic trading. However, there is some evidence that algorithmic trading has led to market growth, such that opportunities remain for manual investors, although these are typically for lower quality loans as measured by default risk and yield.

\section{Literature review and theoretical foundation}

\subsection{Investor decision making in online peer- to-peer lending markets}

Manual investors tend to rely on both traditional financial information and "soft" information to make investment decisions [3]. In addition to traditional financial information, the decision making process is influenced (and biased sometimes) by several factors, including peer decisions, borrowers' friendship networks, loan descriptions, geographical distance, cultural distance, political distance, and borrowers' appearance, gender, and race [4-15]. Some recent studies distinguish sophisticated investors from manual investors and find that they rely on different information to screen loans or projects, but their investing performance is not necessarily different [1618]. Although there is some evidence that sophisticated investors might evaluate borrowers differently, it is unclear how this difference affects market opportunities for different types of investors.

\subsection{Algorithmic trading in equity markets}

Algorithmic trading refers to "the use of computer systems to execute trading strategies" [1] or "any form of trading using sophisticated algorithms (programmed systems) to automate all or some part of the trade cycle" [19]. Algorithmic traders may be both faster-acting and better-informed than manual traders [2]. Algorithmic traders can act faster because their trades are executed automatically based on decision rules, and they may be better informed because trades are based on statistical models fed by rich market data. Algorithmic trading improves price efficiency, reduces price discovery and information acquisition, and increases market liquidity [1, 20]. These findings stem largely from stock markets where algorithmic investors can provide liquidity by buying and selling stocks without necessarily eliminating opportunities for manual investors to also buy and sell. However, it is unclear what the impact of algorithmic trading would be in a market where algorithmic investors compete with manual investors for a fixed set of assets, such as for loans in the peer-to-peer lending context. Accordingly, we investigate the implications of algorithmic trading on an understudied outcome, i.e. investors' participation.

\subsection{How Algorithmic trading might influence investor participation}

The basic components of algorithmic trading are automation and information [2]. The automation component means that most or all of the trade is executed by automated systems and technologies. In the context of online lending, automation enables investors to automate their investment decisions rather than manually logging into the platform, picking loans, and placing orders. Therefore, automation should speed up funding time, which becomes our first hypothesis (H1): algorithmic trading can decrease loan funding time. The information component means that investors use models/algorithms to analyze information to evaluate and select borrowers. Because it is widely expected that data-driven statistical models can improve decision efficiency and accuracy, we hypothesize that algorithmic trading can improve investment performance, i.e. the performance of loans selected by algorithms should be higher (H2). Combining $\mathrm{H} 1$ and $\mathrm{H} 2$, it is reasonable to expect that manual investors would be crowded out of the best, most quickly-funded loans. We thus propose the third hypothesis (H3): algorithmic trading decreases the number of investors of "flash" loans, which we use to denote the top $20 \%$ of loans in terms of funding time, from fastest to slowest.

Besides a direct impact, algorithmic trading might also indirectly influence the whole market. This might occur if algorithmic trading decreases funding time and increases decision efficiency. Decreased funding time might retain/attract more borrowers to online lending platforms. Increased decision efficiency 
(either real or perceived) might increase investors' confidence and motivate them to fund more borrowers, especially those risky borrowers in whom they otherwise won't invest. These two effects could lead to a larger market size, which is our fourth hypothesis (H4). Because H3 suggests less investor participation while $\mathrm{H} 4$ suggests more, there is no prior theoretical expectation for the overall impact of algorithmic trading on investor participation. Therefore, we propose our final hypothesis in a nondirectional way, saying algorithmic trading might either increase or decrease investor participation (H5). Table 1 summarizes these five hypotheses.

Table 1. Research hypotheses

H1 Algorithmic trading reduces loan funding time.

H2 Algorithmic trading increases lending performance.

H3 Algorithmic trading reduces number of investors.

H4 Algorithmic trading increases market size.

H5 Algorithmic trading increases or decreases the overall investor participation.

\section{Empirical setting and data 3.1. Empirical setting}

The focal online lending platform that we study is Prosper.com. Prosper.com operates in the following way (since 2011): (1) borrowers submit their loan requests and personal financial information to Prosper.com; (2) Prosper.com underwrites the requests (to set the interest rate) and posts the loan requests (i.e., "listings"); (3) investors choose which borrowers to fund and how much to fund; and (4) borrowers receive their loans if they attract enough investment (either $70 \%$ or $100 \%$ of the requested amount, depending on borrower's choice). Initially, step 3 was conducted manually by investors. Currently, much of step 3 is conducted via algorithmic trading in which sophisticated investors use data provided by Prosper.com (perhaps combined with other data) to automatically select and fund loans.

\subsection{Data and variables}

We gathered a dataset of 63,706 loans funded through Prosper.com from 2011 to 2013. We created several variables to describe each loan. Funding time is the difference between when the loan was first posted and when it was funded. We created two measures of investor concentration per loan: Number of investors is the number of investors per loan, and average funding amount is the average amount that each investor invested in the loan. We measured each loan's performance via compound annual growth rate (CAGR) and internal rate of return (IRR) as well as whether the borrower defaulted on the loan (default status). We use the following as control variables: loan interest rate, amount borrowed, monthly payment, and several variables about the borrower, including monthly income, debt-to-income ratio (including the loan), months employed, number of credit inquires in the last 6 months, and open credit lines. Table 2 provides descriptive statistics of this dataset.

Table 2. Descriptive statistics

\begin{tabular}{|c|c|c|}
\hline Variable & Mean & Std. Dev. \\
\hline \multicolumn{3}{|l|}{ Loan Funding Variables } \\
\hline Funding time (in hours) & 48.48 & 80.92 \\
\hline Funding time (in logged seconds) & 8.55 & 4.06 \\
\hline Number of investors & 66.66 & 90.06 \\
\hline $\begin{array}{l}\text { Average funding amount per } \\
\text { investor }\end{array}$ & $3,227.27$ & $5,902.76$ \\
\hline Amount borrowed & $9,045.99$ & $6,147.36$ \\
\hline Interest rate & 0.202 & 0.072 \\
\hline \multicolumn{3}{|l|}{ Loan Performance Variables } \\
\hline $\begin{array}{l}\text { Compound annual growth rate } \\
\text { (CAGR) }\end{array}$ & 0.023 & 0.141 \\
\hline Internal rate of return (IRR) & 0.050 & 0.185 \\
\hline Default status & 0.204 & 0.403 \\
\hline \multicolumn{3}{|l|}{ Loan Credit Variables } \\
\hline FICO score & 697 & 38.751 \\
\hline Monthly payment (in \$1,000) & 0.294 & 0.183 \\
\hline $\begin{array}{l}\text { Borrower stated monthly income } \\
\text { (in } \$ 1,000)\end{array}$ & 5.921 & 9.161 \\
\hline Debt-to-income ratio & 0.401 & 0.512 \\
\hline Months employed & 104.433 & 97.415 \\
\hline Inquires in last 6 months & 0.981 & 1.427 \\
\hline Open credit lines & 9.426 & 4.912 \\
\hline
\end{tabular}

Notes: This dataset contains 63,706 loans that are (1)

eventually issued and (2) listed on Prosper platform from

2011 to 2013. Debt-to-income ratio is capped at 2.

We also gathered a complementary dataset of all listings that appeared on Prosper.com during the same period. Not all listings become funded loans. Listings may expire (if a listing fails to pass the funding threshold), be canceled by Prosper.com (if a listing is incomplete or contains incorrect information), or be withdrawn (if the borrower withdraws the loan application due to personal reasons). This dataset allows us examine changes in the size of the market.

\section{Empirical strategy, analysis, and results}

Because we cannot directly observe investors' use of algorithmic trading technologies, we study the effect of a major upgrade to Prosper's API on March 11, 2013 that facilitated algorithmic trading. This upgrade yielded three key improvements. First, the data structure exposed by the API became more userfriendly, such that investors could use the API more 
easily. In addition, the API became faster and more responsive. Second, approximately 460 new data elements were made available through the API, thereby permitting more sophisticated loan-selection models. Third, the API allowed investors to use thirdparty tools, thereby providing more options for investors to use API.

\subsection{Model free evidence}

We first investigated the funding time of loans across time. We classified funded loans into three categories based on how fast they got funded: top 20\% ("flash" loans), the middle $60 \%$, and the bottom $20 \%$ ("leftover" loans). Panels A, B, and C of Figure 1 show the median funding time of each group day by day from January 1, 2013 to March 31, 2013 (because the whole lone program was launched April 2013 so we excluded observations after March 31 to avoid confounding effects). A notable pattern is that funding time of "flash" loans drops significantly after the new API was released on March 11, but the funding time of "leftover" loans is almost unchanged. Panel D of Figure 1 shows the percentage of loans that get funded within 60 seconds, 10 minutes, and 1 hour across time. By the end of March 2013, about $10 \%$ of loans are funded in 60 seconds and $30 \%$ of loans are funded in 10 minutes. This suggests that these loans are being funded algorithmically, given that manual investors are unlikely to be able to fund loans this quickly.
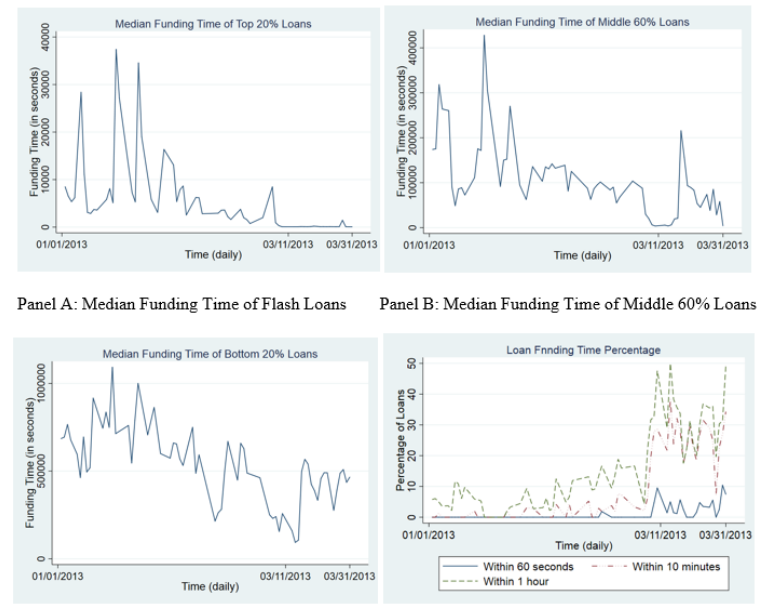

Panel C: Median Funding Time of Leftover Loans Panel D: Loan Funding Time Percentage

Figure 1. Funding time by group across time

We next investigated investor concentration in loans over time. Panel A of Figure 2 shows the median number of investors per loan of each group from January 1, 2013 to March 31, 2013 while Panels B, C, and $\mathrm{D}$ of Figure 2 show the median average funding amount per investor per loan. After the new API was released on March 11, fewer investors share in "flash" loans or in the middle $60 \%$ of loans. This suggests that these loans are being funded by institutional investors who provide a larger portion of the loan fund.

\subsection{Empirical Strategy}

To better identify the effect of the API upgrade, we use a difference-in-differences strategy, which is widely used in studies about platform implementation, policy change or technology change [21-23]. As shown in the model-free analysis, the "leftover" loans (i.e., those funded last) were largely unaffected by the API upgrade. We believe that this is because these loans are typically funded by manual investors who are not influenced by the API upgrade (because they don't use the API). Thus, we use "leftover" loans as the control group. Conversely, the "flash" loans appear to be affected by the API upgrade, and we consider them to be the treated group. The difference-indifferences approach allows us to separate the effect of any general supply or demand shock or macroeconomic trend (which should affect both "flash" and "leftover" loans) from the effect of the API upgrade (which should not affect "leftover" loans). We use the middle $60 \%$ of loans as a secondary treatment group. Including them allows us to check the proposed mechanism, because we expect them to be affected in the same direction as the "flash" loans but with a smaller magnitude. It is worth noting that the "leftover" loans don't serve as a strict control group because they are also influenced by the API upgrade. If we assume the impacts of the API upgrade have the same direction on all three groups, we actually underestimate the impact of API upgrade by viewing "leftover" loans as the control group.
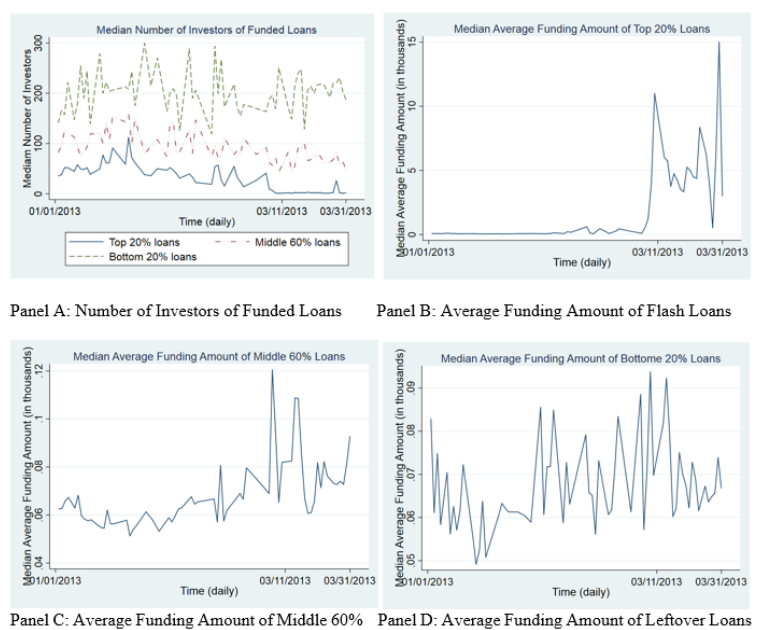

Figure 2. Funding time and investor concentration 
To avoid conflating our analysis with other policy changes made by Prosper.com, we restricted our analysis to the days close to the March 11, 2013 treatment date. At the month level, we define February 2013 as the pre-treatment period while March 2013 as the post-treatment period. We only show analysis results at the month level, but our findings are also robust at day level. Flash (i.e. top $20 \%$ ), middle $60 \%$, and leftover (i.e. bottom $20 \%$ ) are defined based on funding time ranking within each month. The basic DID model is shown in specification (1).

$$
Y_{i t}=\alpha+\beta_{1} \text { LoanGroup }_{i}+
$$$$
\beta_{2} \text { PostTreatment }_{t}+\beta_{3} \text { DID }_{i t}+\gamma_{1} X_{i}+\varepsilon_{i t}
$$

$Y_{i t}$ indicates the outcome variables including funding time, number of investors, average funding amount per investor and loan performance measures such as CAGR, IRR, and default. Due to the skewed distribution and the between-group variation of funding time, number of investors, and average funding amount per investor, we use the natural log of each as the dependent variable. LoanGroup $i$ indicates whether loan i belongs to the top $20 \%$ in terms of funding time ("flash" loans), the middle $60 \%$, or the bottom $20 \%$ ("leftover" loans). When estimating the model, we use the "leftover" loans as the baseline group. PostTreatment $t_{t}$ is defined as 1 if a loan was listed after the treatment and 0 otherwise. DID $D_{i t}$ is the interaction of LoanGroup $_{i}$ and PostTreatment ${ }_{t} . X_{i}$ controls for other factors that might influence the dependent variables (see Table2). Time fixed effects are not included because they are collinear with PostTreatment $_{t}$ in the monthly analysis.

Specification (1) is designed to test hypotheses 1 to 3 , which are about the direct impacts of algorithmic trading on loan outcomes. We test hypothesis 4 via conditional correlations rather than a DID model, given that we lack a control group.

$$
Y_{i t}=\alpha+\beta_{1} \text { PostTreatment }_{t}+\gamma_{1} X_{i}+
$$

$\gamma_{2}$ Time $_{t}+\varepsilon_{i t}$

$Y_{i t}$ is an indicator of listing success, measured as whether the listing passes the funding threshold (passing funding threshold) and the actual funding percentage (funding percentage). This model simply tests whether listings are more likely to become loans after the API upgrade. This allows us to test whether the API upgrade increases the number of available loans, thereby increasing the market size. We consider alternative explanations for market growth (e.g., increased number of investors) via robustness checks. We find that the API upgrade also changes the "taste" of investors, which is not likely to be a consequence of increased investor money (details not included due to space limitations).

Although we don't observe a direct transfer from manual lending to algorithmic trading, the API upgrade can fairly represent this situation because before the API upgrade few investors were using the API so the general environment was close enough to manual lending.

\subsection{Main results}

The results of our tests of $\mathrm{H} 1$ to $\mathrm{H} 3$ are shown in Tables 3 and 4. They are estimated based on specification (1) and support H1. Column 1 of Table 3 show that after the API upgrade, "flash" loans get funded much faster. The coefficient for the "flash" loan group after the API treatment is -3.179 and significant. This reduces the funding time of "flash" loans by $95.8 \%\left(\mathrm{e}^{-3.179}-1\right)$; the corresponding reduction for middle $60 \%$ loans is $62.7 \%\left(\mathrm{e}^{-0.985}-1\right)$. Considering the mean funding time for "flash" loans is 4,032 seconds pre-treatment, the effect amounts to eliminating 3,862 seconds.

Table 3. DID analysis on funding time and investor concentration

\begin{tabular}{|l|c|c|c|}
\hline \multicolumn{1}{|c|}{$\begin{array}{c}\text { Outcome } \\
\text { Variable }\end{array}$} & $\begin{array}{c}\text { Log } \\
\text { (Funding } \\
\text { Time in } \\
\text { Seconds) }\end{array}$ & $\begin{array}{c}\text { Log } \\
\text { (Number of } \\
\text { Investors) }\end{array}$ & $\begin{array}{c}\text { Log } \\
\text { (Average } \\
\text { Funding } \\
\text { Amount) }\end{array}$ \\
\hline Post treatment & $\begin{array}{c}-0.303^{* * *} \\
(0.037)\end{array}$ & $\begin{array}{c}0.012 \\
(0.031)\end{array}$ & $\begin{array}{c}0.000 \\
(0.036)\end{array}$ \\
\hline $\begin{array}{l}\text { Loan group: Flash } \\
\text { loans }\end{array}$ & $\begin{array}{c}-5.016^{* * *} \\
(0.110)\end{array}$ & $\begin{array}{c}-1.501^{* * *} \\
(0.075)\end{array}$ & $\begin{array}{c}1.399^{* * *} \\
(0.077)\end{array}$ \\
\hline $\begin{array}{l}\text { Loan group: } \\
\text { Middle 60\% }\end{array}$ & $\begin{array}{c}-1.557^{* * *} \\
(0.056)\end{array}$ & $\begin{array}{c}-0.348^{* * *} \\
(0.039)\end{array}$ & $\begin{array}{c}0.350^{* * *} \\
(0.041)\end{array}$ \\
\hline $\begin{array}{l}\text { Loan group: Flash } \\
\text { loans } * \text { post } \\
\text { treatment }\end{array}$ & $\begin{array}{c}-3.179^{* * *} \\
(0.114)\end{array}$ & $\begin{array}{c}-2.760^{* * *} \\
(0.089)\end{array}$ & $\begin{array}{c}2.835^{* * *} \\
(0.093)\end{array}$ \\
\hline $\begin{array}{l}\text { Loan group: } \\
\text { Middle 60\% } * \\
\text { post treatment }\end{array}$ & $\begin{array}{c}-0.985^{* * *} \\
(0.077)\end{array}$ & $\begin{array}{c}-0.418^{* * *} \\
(0.045)\end{array}$ & $\begin{array}{c}0.394^{* * *} \\
(0.047)\end{array}$ \\
\hline Control variables & $\sqrt{ }$ & $\sqrt{ }$ & $\sqrt{ }$ \\
\hline $\begin{array}{l}\text { Loan term fixed } \\
\text { effects }\end{array}$ & $\sqrt{ }$ & $\sqrt{ }$ & $\sqrt{ }$ \\
\hline $\begin{array}{l}\text { Loan grade fixed } \\
\text { effects }\end{array}$ & $\sqrt{ }$ & $\sqrt{ }$ & $\sqrt{ }$ \\
\hline \# of observations & 2,581 & 2,581 & 2,581 \\
\hline $\mathrm{R}^{2}$ & 0.8109 & 0.8049 & 0.8045 \\
\hline
\end{tabular}

Notes: ${ }^{* * *} \mathrm{p}<0.01 ; * * \mathrm{p}<0.05 ;{ }^{*} \mathrm{p}<0.1$. Robust standard errors are reported in parentheses.

H3 is also supported. Columns 2 and 3 in Table 3 show that after the API upgrade, both "flash" loans and middle $60 \%$ loans have fewer investors and a larger average funding amount per investor. For "flash" loans, the number of investors decreases by $93.7 \%$ $\left(\mathrm{e}^{-2.760}-1\right)$ and the average funding amount per investor increases by $1603 \%\left(\mathrm{e}^{2.835}-1\right)$. Considering the mean number of investors is 40 pre-treatment, the decrease implies that approximately 37 investors are 
crowded out of "flash" loans after the API upgrade. Middle $60 \%$ loans also experience a $34.2 \%$ decrease in number of investors and a $48.3 \%$ increase in average funding amount per investor.

Table 4 shows the results of our tests of $\mathrm{H} 2$. Because algorithmic investors might have different loan preferences than manual investors (e.g. algorithmic investors might invest in only loans of grade $\mathrm{C}, \mathrm{D}, \mathrm{E}$, and $\mathrm{HR}$ while manual investors might invest in only loans of grade AA, A, B, C, and D), we test $\mathrm{H} 2$ by examining both absolute performance and within loan grade performance (but we only show results on absolute performance analysis due to space limitation). We find weak to no evidence for $\mathrm{H} 2$. The API upgrade doesn't significantly affect the performance difference between "flash" loans and "leftover" loans. As shown below, this is likely because "flash" loans have always outperformed "leftover" loans: the API upgrade did not increase this performance gap.

Table 4. DID analysis on lending performance

\begin{tabular}{|l|c|c|c|}
\hline \multicolumn{1}{|c|}{$\begin{array}{c}\text { Outcome } \\
\text { Variable }\end{array}$} & CAGR & IRR & Default \\
\hline Post treatment & $\begin{array}{c}-0.006 \\
(0.010)\end{array}$ & $\begin{array}{c}-0.011 \\
(0.013)\end{array}$ & $\begin{array}{c}0.022 \\
(0.036)\end{array}$ \\
\hline $\begin{array}{l}\text { Loan group: } \\
\text { Flash loans }\end{array}$ & $\begin{array}{c}0.001 \\
(0.012)\end{array}$ & $\begin{array}{c}-0.001 \\
(0.015)\end{array}$ & $\begin{array}{c}-0.021 \\
(0.038)\end{array}$ \\
\hline $\begin{array}{l}\text { Loan group: } \\
\text { Middle 60\% }\end{array}$ & $\begin{array}{c}-0.000 \\
(0.009)\end{array}$ & $\begin{array}{c}0.000 \\
(0.013)\end{array}$ & $\begin{array}{c}-0.028 \\
(0.032)\end{array}$ \\
\hline $\begin{array}{l}\text { Loan group: } \\
\text { Flash loans } * \\
\text { post treatment }\end{array}$ & $\begin{array}{c}0.005 \\
(0.015)\end{array}$ & $\begin{array}{c}0.015 \\
(0.020)\end{array}$ & $\begin{array}{c}-0.065 \\
(0.049)\end{array}$ \\
\hline $\begin{array}{l}\text { Loan group: } \\
\text { Middle 60\% } * \\
\text { post treatment }\end{array}$ & $\begin{array}{c}0.018^{\mathrm{a}} \\
(0.012)\end{array}$ & $\begin{array}{c}0.026^{*} \\
(0.016)\end{array}$ & $\begin{array}{c}-0.028 \\
(0.041)\end{array}$ \\
\hline $\begin{array}{l}\text { Loan term } \\
\text { fixed effects }\end{array}$ & & & $\sqrt{ }$ \\
\hline $\begin{array}{l}\text { Loan grade } \\
\text { fixed effects }\end{array}$ & & & $\sqrt{ }$ \\
\hline $\begin{array}{l}\text { \# of } \\
\text { observations }\end{array}$ & 2,626 & 2,626 & 2,626 \\
\hline $\mathrm{R}^{2}$ & 0.0029 & 0.0032 & 0.0504 \\
\hline
\end{tabular}

Notes: ${ }^{* * *} \mathrm{p}<0.01 ;{ }^{* *} \mathrm{p}<0.05 ;{ }^{*} \mathrm{p}<0.1$. Robust standard errors are reported in parentheses. a $p$ value $=0.119$.

Table 5 shows the results of our tests of $\mathrm{H} 4$, which were estimated from specification (2). This analysis is based on the listing dataset rather than the loan dataset used for testing $\mathrm{H} 1$ to $\mathrm{H} 3$. The coefficients for Post treatment are always positive and significant, indicating that after the API upgrade more loans are funded. Considering the pre-treatment means of funding percentage and passing funding threshold are 0.871 and 0.847 , the 0.029 coefficient in column 1 represents a $3.3 \%$ increase in funding percentage while the 0.034 coefficient in column 2 represents a
$4.0 \%$ increase in funding likelihood. This suggests that the API upgrade corresponds to an increase in market size. It is possible that other events that occurred at a similar time as the API upgrade might explain this finding. However, the relatively narrow time window that we use helps to make this less likely.

Table 5. Before/after treatment analysis on funding percentage

\begin{tabular}{|l|c|c|}
\hline Outcome Variable & $\begin{array}{c}\text { Funding } \\
\text { Percentage }\end{array}$ & $\begin{array}{c}\text { Passing Funding } \\
\text { Threshold }\end{array}$ \\
\hline Post treatment & $\begin{array}{c}0.029^{* * *} \\
(0.009)\end{array}$ & $\begin{array}{c}0.034^{* * *} \\
(0.011)\end{array}$ \\
\hline Control Variables & $\sqrt{ }$ & $\sqrt{ }$ \\
\hline $\begin{array}{l}\text { Loan Term Fixed } \\
\text { Effects }\end{array}$ & $\sqrt{ }$ & $\sqrt{ }$ \\
\hline $\begin{array}{l}\text { Loan Grade Fixed } \\
\text { Effects }\end{array}$ & $\sqrt{ }$ & $\sqrt{ }$ \\
\hline \# of observations & 4,248 & 4,248 \\
\hline $\mathrm{R}^{2}$ & 0.0206 & 0.0311 \\
\hline
\end{tabular}

Notes: ${ }^{* * *} \mathrm{p}<0.01 ; * * \mathrm{p}<0.05 ; * \mathrm{p}<0.1$. Robust standard errors are reported in parentheses.

The main results can be explained by two channels that are brought by API upgrade, which are automated decision making and data-driven decision making. Automated decision making is likely contributing to reduced funding time while datadriven decision making is likely contributing to increased lending performance. It is hard to say to what extent each of them contributes to the results and whether only a combination of them can lead to all the observed results. This is an open question for future research.

\subsection{Robustness checks and additional analysis}

The previous results suggest that algorithmic trading reduces loan funding time, increases investor concentration, and increases the market size. Although the DID design can rule out the influence of trends that affect all loan groups equally, it is still possible that there are some confounding events that influence these groups differently. One major concern is the inflow of large amounts of investor money, which might yield similar results as those that we find. To rule out this alternative explanation, we analyzed one event in which large amount of investor money became available in the market. In May 2011, a large institutional investor made a $\$ 150$ million investment commitment to Prosper. We viewed this events as a treatment that affected the Prosper investment pool and replicated our DID analysis using the months around this treatment. The results in Table 6 indicate that the treatment effects are similar to those that reported in Table 3. However, the magnitude is far 
smaller: for "flash" loans, there is no significant change in funding time, a $15.0 \%$ decrease in number of investors, and a $17.6 \%$ increase in average funding amount per investor. The corresponding magnitudes from Table 3 are $95.8 \%, 93.7 \%$, and $1603 \%$. Therefore, even if the API upgrade happened to coincide with a huge inflow of investor money, our effect is unlikely to be explained solely by the inflow of investor money.

Table 6. Impacts of the inflow of large amounts of investor money

\begin{tabular}{|l|c|c|c|}
\hline \multicolumn{1}{|c|}{$\begin{array}{c}\text { Outcome } \\
\text { Variable }\end{array}$} & $\begin{array}{c}\text { Log } \\
\text { (Funding } \\
\text { Time in } \\
\text { Seconds) }\end{array}$ & $\begin{array}{c}\text { Log } \\
\text { (Number of } \\
\text { Investors) }\end{array}$ & $\begin{array}{c}\text { Log } \\
\text { (Average } \\
\text { Funding } \\
\text { Amount) }\end{array}$ \\
\hline Post treatment & $\begin{array}{c}-0.012 \\
(0.023)\end{array}$ & $\begin{array}{c}-0.127^{* * *} \\
(0.028)\end{array}$ & $\begin{array}{c}0.125^{* * *} \\
(0.028)\end{array}$ \\
\hline $\begin{array}{l}\text { Loan group: Flash } \\
\text { loans }\end{array}$ & $\begin{array}{c}-3.415^{* * *} \\
(0.108)\end{array}$ & $\begin{array}{c}-1.008^{* * *} \\
(0.056)\end{array}$ & $\begin{array}{c}0.884^{* * *} \\
(0.056)\end{array}$ \\
\hline $\begin{array}{l}\text { Loan group: } \\
\text { Middle 60\% }\end{array}$ & $\begin{array}{c}-0.589^{* * *} \\
(0.027)\end{array}$ & $\begin{array}{c}-0.358^{* * *} \\
(0.025)\end{array}$ & $\begin{array}{c}0.345^{* * *} \\
(0.024)\end{array}$ \\
\hline $\begin{array}{l}\text { Loan group: Flash } \\
\text { loans } * \text { post } \\
\text { treatment }\end{array}$ & $\begin{array}{c}0.021 \\
(0.141)\end{array}$ & $\begin{array}{c}-0.163^{* *} \\
(0.072)\end{array}$ & $\begin{array}{c}0.162^{* *} \\
(0.072)\end{array}$ \\
\hline $\begin{array}{l}\text { Loan group: } \\
\text { Middle 60\% } \\
\text { post treatment }\end{array}$ & $\begin{array}{c}-0.092^{* * *} \\
(0.035)\end{array}$ & $\begin{array}{c}-0.119^{* * *} \\
(0.035)\end{array}$ & $\begin{array}{c}0.099^{* * *} \\
(0.035)\end{array}$ \\
\hline Control variables & $\sqrt{ }$ & $\sqrt{ }$ & $\sqrt{ }$ \\
\hline $\begin{array}{l}\text { Loan term fixed } \\
\text { effects }\end{array}$ & $\sqrt{ }$ & $\sqrt{ }$ & $\sqrt{ }$ \\
\hline $\begin{array}{l}\text { Loan grade fixed } \\
\text { effects }\end{array}$ & $\sqrt{ }$ & $\sqrt{ }$ & $\sqrt{ }$ \\
\hline \# of observations & 2,818 & 2,818 & 2,818 \\
\hline $\mathrm{R}^{2}$ & 0.7034 & 0.6546 & 0.3485 \\
\hline
\end{tabular}

Notes: $* * * \mathrm{p}<0.01 ; * * \mathrm{p}<0.05 ; * \mathrm{p}<0.1$. Robust standard errors are reported in parentheses. This analysis is conducted at monthly level.

Regarding investment performance, we find no support that algorithmic trading improves investment performance. To explore this, we conducted an additional analysis. It is possible that "flash" loans have always outperformed "leftover" loans, and this performance difference is not enlarged by the API upgrade. In Table 7 we simply compare the performance of "flash" loans, middle $60 \%$ loans, and "leftover" loans in the year 2013. "Flash" loans (as well as middle $60 \%$ loans) outperform "leftover" loans: they have a $26.8 \%(0.009 / 0.038)$ advantage in CAGR, a $23.1 \%(0.015 / 0.065)$ advantage in IRR, and an $11.1 \%(0.028 / 0.252)$ advantage in default rate (i.e. lower default rate). When funding time is used as the key independent variable, the results are the same (unreported but available upon request): slower funding time predicts poorer performance. Given these findings, we conclude that the API upgrade doesn't bring in an additional performance advantage for "flash" loans compared to "leftover" loans (at least not in the short term around the API upgrade).

Table 7. Funding time, algorithmic trading, and lending performance

\begin{tabular}{|l|c|c|c|}
\hline $\begin{array}{c}\text { Outcome } \\
\text { Variable }\end{array}$ & CAGR & IRR & Default \\
\hline $\begin{array}{l}\text { Loan group: } \\
\text { Flash loans }\end{array}$ & $\begin{array}{l}0.009^{* *} \\
(0.003)\end{array}$ & $\begin{array}{c}0.015^{* * *} \\
(0.004)\end{array}$ & $\begin{array}{c}-0.028^{* *} \\
(0.010)\end{array}$ \\
\hline $\begin{array}{l}\text { Loan group: } \\
\text { Middle 60\% }\end{array}$ & $\begin{array}{c}0.007^{* * *} \\
(0.001)\end{array}$ & $\begin{array}{c}0.015^{* * *} \\
(0.001)\end{array}$ & $\begin{array}{c}-0.019^{* * *} \\
(0.005)\end{array}$ \\
\hline Constant & $\begin{array}{c}0.038^{* * *} \\
(0.001)\end{array}$ & $\begin{array}{c}0.065^{* * *} \\
(0.001)\end{array}$ & $\begin{array}{c}0.252^{* * *} \\
(0.018)\end{array}$ \\
\hline $\begin{array}{l}\text { Loan grade fixed } \\
\text { effects }\end{array}$ & & & $\sqrt{ }$ \\
\hline Time fixed & $\sqrt{ }$ & $\sqrt{ }$ & $\sqrt{ }$ \\
\hline effects & 20,183 & 20,183 & 20,183 \\
\hline \# of observations & 0.0034 & 0.0051 & 0.0355 \\
\hline $\mathrm{R}^{2}$ & & $\mathrm{p}$ & \\
\hline
\end{tabular}

Notes: $* * * \mathrm{p}<0.01 ; * * \mathrm{p}<0.05 ; * \mathrm{p}<0.1$. Standard errors in parentheses are clustered at month level. All models don't include credit information (to check absolute performance).

\subsection{Implications for investor participation}

Our results indicate that algorithmic trading crowds out manual investors from "flash" loans and middle $60 \%$ loans but also increases the market size. Thus, it is not clear whether the absolute number of loans available to manual investors increases or decreases. Unfortunately, we cannot observe the total investment amount from manual investors. Instead, we create two proxy indicators for "crowd" loans, i.e., loans funded by manual investors. In the first approach, we define a loan as a "crowd" loan when the average funding amount per investor is less than $\$ 100$. We then count both the number of "crowd" loans and the percentage of "crowd" loans per day before and after the API upgrade. Panel A of Figure 3 shows the result. The second approach (the results of which are shown in Panel B of Figure 3) is similar, except that we define a loan as a "crowd" loan if the number of investors exceeds 100 . With both measures, the number of "crowd" loans increases after the API upgrade, but the percentage of "crowd" loans decreases. This suggests that even though manual investors are being crowded out of some loans, market growth allows them to continue to invest in the market. 


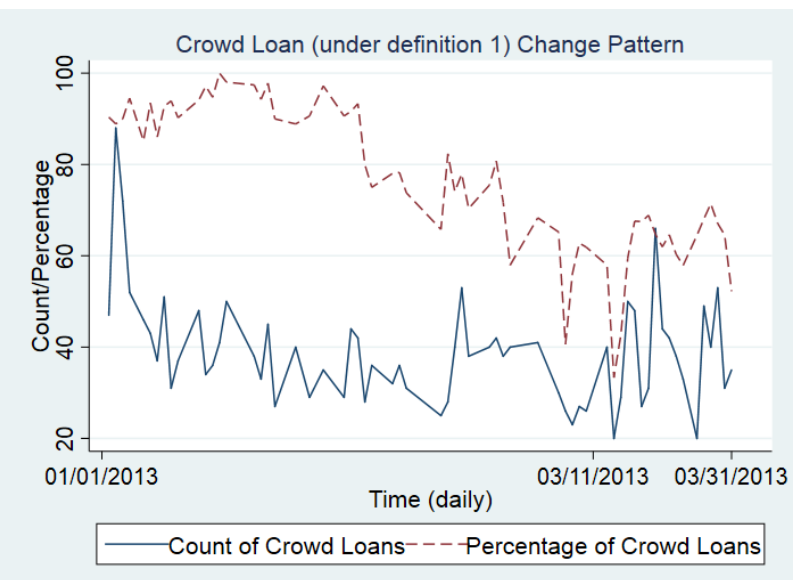

Panel A: "Crowd" loans under definition 1

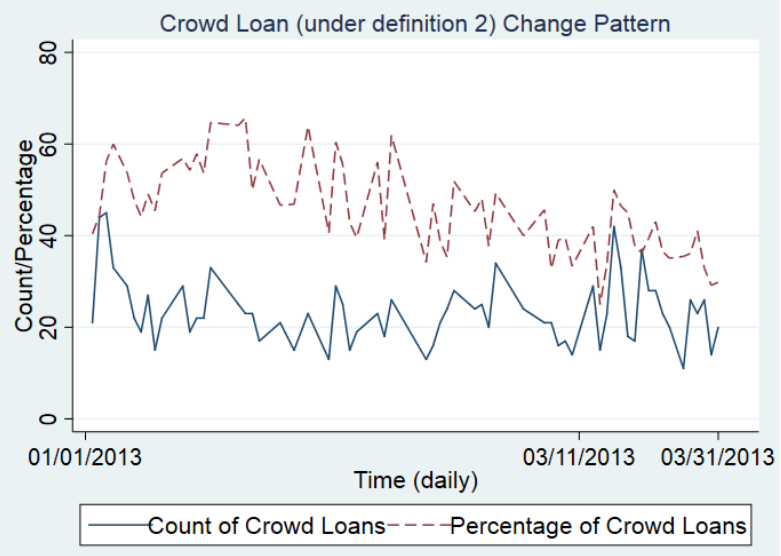

Panel B: "Crowd" loans under definition 2

Figure 3. Total number and share of "crowd" loans

Although the quantity of loans available to manual investors may not suffer from algorithmic trading, the quality of loans might suffer. Because manual investors are crowded out of "flash" loans and middle $60 \%$ loans, and because "flash" loans and middle $60 \%$ loans always outperform "leftover" loans, it is reasonable to expect that loans available to manual investors are inferior. We test this directly in Table 8 and Table 9. In Table 8, the number of investors is the key independent variable while in Table 9 the crowd loan dummy variable (using definition 1 from above) is the key independent variable. Under both approaches the "crowd" loans available to manual investors almost always perform worse than loans funded by fewer investors. Based on the results in column 2 in Table 8, compared with a loan funded by 1 investor, a loan funded by 101 investors has a lower IRR with a $0.008\left(0.00008^{*} 100\right)$ rate difference, indicating a $14.5 \%(0.008 / 0.055)$ performance decline. Column 2 in Table 9 shows a similar result, implying a $19.2 \%(0.01 / 0.052)$ performance decline. In addition, "crowd" loans experience an additional performance decline after the API upgrade, although the decline is not always significant.

Table 8. Performance of "crowd" loans (number of investor as key independent variable )

\begin{tabular}{|l|c|c|c|}
\hline Outcome Variable & CAGR & IRR & Default \\
\hline Post treatment & $\begin{array}{c}0.004^{* * *} \\
(0.001)\end{array}$ & $\begin{array}{c}-0.003^{* *} \\
(0.001)\end{array}$ & $\begin{array}{c}-0.041^{* * *} \\
(0.005)\end{array}$ \\
\hline Number of investor & $-0.00002^{*}$ & $-0.00008^{* * *}$ & $0.0002^{* * *}$ \\
$(0.00001)$ & $(0.00002)$ & $(0.0000)$ \\
\hline Number of investor & -0.000 & -0.000 & -0.000 \\
* post treatment $^{(0.000)}$ & $(0.000)$ & $(0.000)$ \\
\hline Constant & $0.038^{* * *}$ & $0.065^{* * *}$ & $0.252^{* * *}$ \\
& $(0.001)$ & $(0.001)$ & $(0.018)$ \\
\hline Loan grade fixed & & & $\sqrt{ }$ \\
\hline effects & & & $\sqrt{ }$ \\
\hline Time fixed effects & $\sqrt{ }$ & $\sqrt{ }$ & $\sqrt{ }$ \\
\hline$\#$ of observations & 29,657 & 29,657 & 29,657 \\
\hline $\mathrm{R}^{2}$ & 0.0035 & 0.0043 & 0.0540 \\
\hline
\end{tabular}

Notes: $* * * \mathrm{p}<0.01 ; * * \mathrm{p}<0.05 ; * \mathrm{p}<0.1$. Standard errors in parentheses are clustered at month level. Credit controls are excluded to check overall performance.

Table 9. Performance of "crowd" loans ("Crowd" loan dummy as key independent variable)

\begin{tabular}{|l|c|c|c|}
\hline Outcome Variable & CAGR & IRR & Default \\
\hline Post treatment & $\begin{array}{c}0.005^{* * *} \\
(0.001)\end{array}$ & $\begin{array}{c}-0.001 \\
(0.001)\end{array}$ & $\begin{array}{c}-0.046^{* * *} \\
(0.003)\end{array}$ \\
\hline Crowd loan & $\begin{array}{c}-0.001 \\
(0.003)\end{array}$ & $\begin{array}{c}-0.010^{* * *} \\
(0.003)\end{array}$ & $\begin{array}{c}0.022^{* * *} \\
(0.007)\end{array}$ \\
\hline Crowd loan * post & $\begin{array}{c}-0.009^{* *} \\
(0.003)\end{array}$ & $\begin{array}{c}-0.012^{* *} \\
(0.004)\end{array}$ & $\begin{array}{c}0.009 \\
(0.008)\end{array}$ \\
\hline treatment & $0.020^{* * *}$ & $0.052^{* * *}$ & $0.194^{* * *}$ \\
$(0.001)$ & $(0.001)$ & $(0.008)$ \\
\hline Constant & & & $\sqrt{ }$ \\
\hline Loan grade fixed & & & $\sqrt{ }$ \\
\hline effects & $\sqrt{ }$ & $\sqrt{ }$ & $\sqrt{ }$ \\
\hline Time fixed effects & 29,657 & 29,657 & 29,657 \\
\hline $\mathrm{R}^{2}$ of observations & 0.0035 & 0.0040 & 0.0539 \\
\hline
\end{tabular}

Notes: $* * * \mathrm{p}<0.01 ; * * \mathrm{p}<0.05 ; * \mathrm{p}<0.1$. Standard errors in parentheses are clustered at month level. Credit controls are excluded to check overall performance.

To summarize the overall implications of algorithmic lending on investor participation, we compare four basic statistics of "flash" loans, middle $60 \%$ loans, and "leftover" loans before and after the API upgrade. In Figure 4, the x-axis represents the natural log of funding time in seconds and the y-axis represents the number of investors. Circle size is proportional to the number of funded loans and a darker color indicates better loan performance. Arrows show the changes triggered by algorithmic trading. Loosely speaking, deep-pocket investors are more likely to be algorithmic investors, so they can funds loans in a faster and smarter way. As a result, they fund the majority of "flash" loans and middle 60\% loans, which typically perform better than "leftover" loans. Individual investors are more likely to be manual 
investors who are crowded out of "flash" and middle $60 \%$ loans by algorithmic investors. Although manual investors may still be able to fully allocate their money, they can only select from "leftover" loans, which harms their investment performance. In a nutshell, algorithmic trading creates a new lending environment: algorithmic investors are likely to achieve high returns at the expense of manual investors, who are likely to receive lower (although perhaps still acceptable) returns.

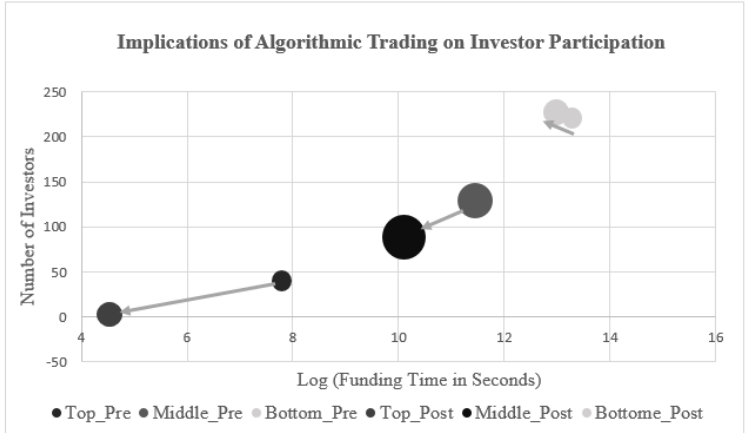

Figure 4. Pattern change of investor participation (pre and post API upgrade)

\section{Conclusion}

Algorithmic trading has great potential to affect investor participation in online lending markets, although the effect is unclear a priori. Leveraging a policy change likely to facilitate algorithmic trading (viz., an API upgrade), we identify the impacts of algorithmic trading on funding time, lending performance, investor concentration, and market size. We find that algorithmic trading significantly reduces the funding time of loans. As a result, manual investors are crowded out of the most quickly-funded and best performing loans. However, manual investors are able to continue investing in the market, given that algorithmic trading appears to increase the market size. However, manual investors are restricted to "leftover" loans, which normally perform worse than other loans. Our findings reveal several promises of algorithmic trading, but they also suggest that algorithmic trading may exacerbate inequality among market participants. Indeed, Prosper.com has launched initiatives to make automated trading tools more accessible to all investors as well as limiting API functionality to reduce the advantages enjoyed by institutional investors. We explored the impact of these initiatives and found that both appear to "level the playing field" (analysis withheld due to the space limitations of the HICSS format but available from authors). This study contributes to several emerging research areas, including online lending, algorithmic trading, data-driven decision making, and more broadly the economics of artificial intelligence. This study also explores means to alleviate the "disparate impact" of algorithmic trading on less sophisticated investors.

\section{References}

[1] Weller, B.M. 2018. "Does Algorithmic Trading Reduce Information Acquisition?" The Review of Financial Studies 31(6), pp. 2184-2226.

[2] Menkveld, A.J. 2016. "The Economics of Highfrequency Trading: Taking Stock," Annual Review of Financial Economics 8, pp. 1-24.

[3] Iyer, R., Khwaja, A.I., Luttmer, E., and Shue, K. 2016. "Screening Peers Softly: Inferring the Quality of Small Borrowers," Management Science 62(6), pp. 1554-1577.

[4] Burtch, G., Ghose, A., and Wattal, S. 2014. "Cultural Differences and Geography as Determinants of Online Prosocial Lending," MIS Quarterly 38(3), pp. 773-794.

[5] Galak, J., Small, D., and Stephen, A.T. 2011. "Microfinance Decision Making: A Field Study of Prosocial Lending," Journal of Marketing Research 48, pp. S130-S137.

[6] Greenberg, J., and Mollick, E. 2017. "Activist Choice Homophily and the Crowdfunding of Female Founders," Administrative Science Quarterly 62(2), pp. 341-374.

[7] Harkness, S.K. 2016. "Discrimination in Lending Markets: Status and the Intersections of Gender and Race," Social Psychology Quarterly 79(1), pp. 81-93.

[8] Hildebrand, T., Puri, M., and Rocholl, J. 2017. "Adverse Incentives in Crowdfunding," Management Science 63(3), pp. 587-608.

[9] Lin, M.F., Prabhala, N.R., and Viswanathan, S. 2013. "Judging Borrowers by the Company They Keep: Friendship Networks and Information Asymmetry in Online Peer-toPeer Lending," Management Science 59(1), pp. 17-35.

[10] Lin, M.F., and Viswanathan, S. 2016. "Home Bias in Online Investments: An Empirical Study of an Online Crowdfunding Market," Management Science 62(5), pp. 1393-1414.

[11] Liu, D., Brass, D.J., Lu, Y., and Chen, D.Y. 2015. "Friendship in Online Peer-to-Peer Lending: Pipes, Prisms, and Relational Herding," MIS Quarterly 39(3), pp. 729-742.

[12] Pope, D.G., and Sydnor, J.R. 2011. "What's in a Picture? Evidence of Discrimination from Prosper.com," The Journal of Human Resources 46(1), pp. 53-92. 
[13] Wang, H.C., and Overby, E. 2018. "Does Political Polarization Decrease Market Efficiency? An Investigation in the Context of Online Lending," working paper.

[14] Younkin, P., and Kuppuswamy, V. 2017. "The Colorblind Crowd? Founder Race and Performance in Crowdfunding," Management Science Articles in Advance.

[15] Zhang, J.J., and Liu, P. 2012. "Rational Herding in Microloan Markets," Management Science 58(5), pp. 892912.

[16] Lin, M.F., Sias, R.W., and Wei, Z.Y. 2018. "The Survival of Noise Traders: Evidence from Peer-to-peer Lending," SSRN working paper available at https://papers.ssrn.com/sol3/papers.cfm?abstract_id=31856 $\underline{08}$.

[17] Mollick, E., and Nanda, R. 2016. "Wisdom or Madness? Comparing Crowds with Expert Evaluation in Funding the Arts," Management Science 62(6), pp. 1533-1553.

[18] Valle, B., and Zeng, Y. 2018. "Marketplace Lending: a New Banking Paradigm?" SSRN working paper available at https://papers.ssrn.com/sol3/papers.cfm?abstract $\mathrm{id}=31029$ $\underline{84}$.

[19] Treleaven, P., Galas, M., and Lalchand, V. 2013. "Algorithmic Trading Review," Communications of the ACM 56(11), pp. 76-85.

[20] Hendershott, T., Jones, C.M., and Menkveld, A.J. 2011. "Does Algorithmic Trading Improve Liquidity?" The Journal of Finance 66(1), pp. 1-33.

[21] Bertrand, M., Duflo, E., and Mullainathan, S. 2004. "How Much Should We Trust Differences-in-differences Estimates?" The Quarterly Journal of Economics 119(1), pp. 249-275.

[22] Greenwood, B.N., and Agarwal, R. 2016. "Matching Platforms and HIV Incidence: An Empirical Investigation of Race, Gender, and Socioeconomic Status," Management Science 62(8), pp. 2281-2303.

[23] Wang, H.C., and Overby, E. 2017. "How Does Online Lending Influence Bankruptcy Filings? Evidence from a Natural Experiment," SSRN working paper available at https://papers.ssrn.com/sol3/papers.cfm?abstract id=29589 $\underline{16}$. 